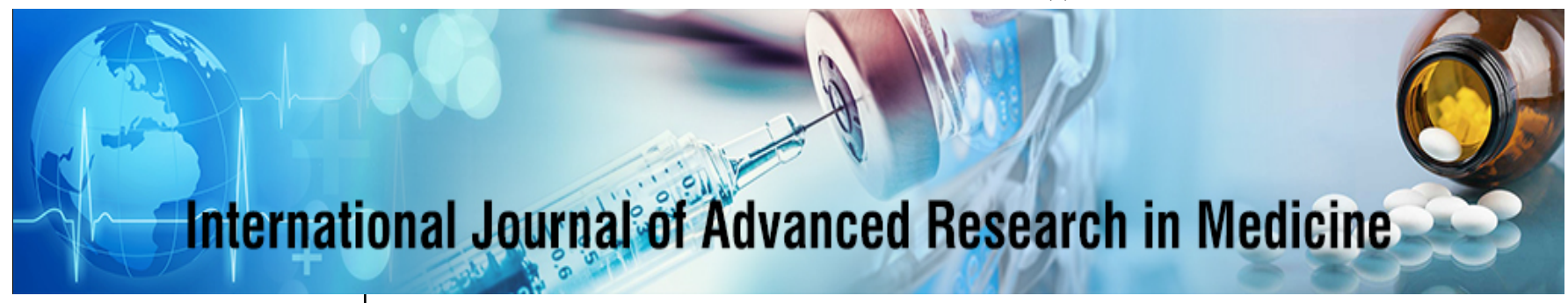

E-ISSN: 2706-9575

P-ISSN: 2706-9567

IJARM 2021; 3(1): 551-555

Received: 22-01-2021

Accepted: 14-03-2021

Dr. Sireesha Gunnam

Assistant Professor,

Department of Nephrology,

NRI Medical College,

Chinakakani, Guntur, Andhra

Pradesh, India

Dr. Raghuram Uppalapati

Assistant Professor,

Department of Pulmonology,

NIMRA Medical College,

Ibrahimpatnam, Vijayawada,

Andhra Pradesh, India

Dr. Gullipalli Prasad

Professor and HOD,

Department of Nephrology,

King George Hospital,

Visakhapatnam, Andhra

Pradesh, India
Corresponding Author:

Dr. Raghuram Uppalapati

Assistant Professor,

Department of Pulmonology,

NIMRA Medical College,

Ibrahimpatnam, Vijayawada,

Andhra Pradesh, India

\section{Analysis of survival factors in dialysis population at a state sponsored free hemodialysis center in India}

\author{
Dr. Sireesha Gunnam, Dr. Raghuram Uppalapati and Dr. Gullipalli \\ Prasad
}

DOI: $\underline{\text { htps://doi.org/10.22271/27069567.2021.v3.i1i.252 }}$

\begin{abstract}
Background: There is rising incidence of chronic kidney disease which poses major problem for both health care and economy in future years. Despite the improvement in quality of dialysis over the past decade, mortality in the ESRD population is high and has been increasing. A 4-year prospective study was conducted at a tertiary care hospital to determine the factors influencing survival among patients on maintenance hemodialysis.

Materials and Methods: A total of 396 patients with end stage renal disease who were started on maintenance hemodialysis twice or thrice weekly over a period of 4 years from May 2016 to May 2020 were studied. Follow up was censored at the time of death or at the end of the 4year study period, whichever occurred first.

Statistical Analysis: The Statistical Package for the Social Sciences version 15.0, Stata 8.0, MedCalc 9.0.1, and Systat 11.0 was used for data analysis.

Results: Of the 396 patients studied (mean age $48.6 \pm 14.55$ years, male: female-2:1 and 51.5\% are diabetics), 213 patients died by end of one year with mortality rate of $53.7 \%$. Chronic interstitial nephritis (34.3\%) is most common etiology. In Cox proportional hazard analyses, patient survival was associated with female sex, low serum albumin, native kidney urine output, presence of left ventricular hypertrophy ( $\mathrm{LVH}$ ) \&ejection fraction $<50 \%$ on two dimensional echocardiography, compliance to dialysis, and interdialytic weight gain $(>3 \mathrm{~kg})$ independently predicted mortality. There was no significant difference between diabetics and non diabetics in relation to death (Relative Risk $=0.214$; $95 \% \mathrm{CI}=0.005-10.02, \mathrm{P}=0.005$ ).

Conclusions: This study revealed that mortality among hemodialysis patients was high in the first 120 days after initiation of dialysis. Female gender, low serum albumin, Low EF $<50 \%$ \& LVH in 2D Echo, low native kidney urine output, poor compliance to dialysis and high interdialytic weight gain $(>3 \mathrm{~kg})$ are associated with increased risk of death. Strategies to prevent cardiovascular events and improve nutrition increases survival outcomes in hemodialysis patients.
\end{abstract}

Keywords: Hemodialysis, mortality, survival

\section{Introduction}

Chronic kidney disease (CKD) is emerging to be an important chronic disease globally ${ }^{[1]}$. The rising incidence of CKD in India poses major burden for both health care and economy in future years. It has been estimated that the age adjusted incidence rate of ESRD in India is about 229 per million population ${ }^{[2]}$ and $>100,000$ new patients enter renal replacement programs annually ${ }^{[3]}$. Approximately fifty years ago, ESRD is invariably lethal. Although maintenance hemodialysis prolonged the life of patients, mortality still remains high. Mortality rates among hemodialysis (HD) patients exceeds $20 \%$ per year ${ }^{[4]}$ and higher mortality rate within first year of initiation of HD has been described ${ }^{[5]}$. Approximately 9$13 \%$ of patients on hemodialysis die within one year ${ }^{[6]}$. The age adjusted all cause mortality rate is 6.3-8.2 times greater for dialysis patients than general population ${ }^{[7]}$.

Despite the improvement in quality of dialysis over the past decade, mortality in the ESRD population is high and has been increasing ${ }^{[8,25]}$. So, newer approaches are required to improve overall mortality rate and achieve an acceptable level of survival and rehabilitation in hemodialysis patients ${ }^{[9]}$. In this study, we analysed the outcome and the factors which had impact on survival of hemodialysis patients.

\section{Materials and Methods}

Patients with ESRD who were started on maintenance hemodialysis were enrolled and studied prospectively over a period of 4 years at king George Hospital, VIshakapatnam. 
Both the patient and his/her relatives were subsequently interviewed and data entered into an electronically compatible proforma. Patients were diagnosed to have ESRD if they had an irreversible decline in renal function (estimated glomerular filtration rate by CKD EPI formula) ${ }^{[10]}$ for more than 3 months. The diagnosis of underlying kidney disease was based on clinical, laboratory and radiological features.

Patients with acute renal failure, those who were dropped out or switched to other forms of renal replacement therapy like continuous ambulatory peritoneal dialysis (CAPD) and renal transplantation, and patients who were positive for HbsAg and Hepatitis $C$ virus were excluded.

At baseline, i.e. 1 month after the start of dialysis, information was collected on the demographic profile, underlying kidney disease and comorbid conditions. At baseline and every 3 months after the start of therapy, information was gathered on the nutritional status (Body mass index BMI), blood pressure, presence or absence of diabetes and investigations including hemoglobin, serum albumin, calcium, phosphorus, 2D Echo features i.e., presence of left ventricular hypertrophy and ejection fraction(EF) $<50 \%$ and hemodialysis characteristics which includes compliance to scheduled sessions of hemodialysis, interdialytic weight gain were noted as per the standard proforma. Those who missed two or more sessions of hemodialysis in a month were considered to be poorly compliant.

The patients were followed till end of the study or until death. At the end of the study period, populationwas divided into two groups based on the survivaltime, i.e. those who survived for at least a period of1 year were considered as survived and those who died within 1 year were considered as died. Allabovementioned clinical, laboratory and dialysisrelated factors were compared between two groups and factors which had an impact on survival were analyzed.

\section{Hemodialysis details}

Standard bicarbonate hemodialysis was performed for 4 hours twice or thrice weekly. Individual proportioning dialysis machines were used with reverse-osmosis treated water. Volumetric ultrafiltration control was available in all the machines. Polysulfone hollow fiber dialyzers of mass transfer area co-efficient of $578 \mathrm{ml} / \mathrm{min}$ (500-600 ml/min) and ultrafiltration co-efficient $5.5 \mathrm{ml} / \mathrm{h} \mathrm{mmHg}$ were used. Dialyzate flow rate was $500 \mathrm{ml} / \mathrm{min}$ and blood flow rates were targeted as per the patient requirement. Dialyzer re-use was uniformly performed using automated methods. Details regarding the type of vascular access, hepatitis B vaccination, erythropoietin use and the complications on hemodialysis including vascular access-related ones were recorded.

\section{Statistical Analysis}

Mean \pm standard deviation (SD) and percentages were used for summarizing the data. Continuous variables were studied using the Student's t-test. Categorical variables were analyzed using the Chi-square and Fisher's exact tests. The primary endpoint of the analysis was death or completion of study period. Cox proportional hazard analysis were used for calculation of survival. Multivariate logistic regression analysis was performed to identify independent predictors of mortality. The confidence interval (CI) was $95 \%$ and a $P<$ 0.05 was used for statistical significance. All statistical analyses were performed with SPSS version 15.0, Stata 8.0, MedCalc 9.0.1 and Systat 11.0.

\section{Results}

A total of 476 patients fulfilled the inclusion criteria. After excluding patients transferred to other hemodialysis centre's, dropouts, renal transplantation, and Continuous Ambulatory Peritoneal Dialysis(CAPD), a total of 396 patients were included in the study. Majority of the patients were above 40 years of age (age $48.6 \pm 14.55$ ) and males outnumbered females in a ratio of 2:1. Diabetics comprised $51.5 \%$ of the patient population. Chronic interstitial nephritis was the most common underlying kidney disease (34.3\%). Chronic glomerulonephritis accounted for 22.2\% of the cases which includes varied causes namely, Ig A nephropathy (2.02\%), Alports syndrome (1.01\%), RPRF (2.5\%). Other causes include Diabetic kidney disease (10.6\%), Autosomal dominant polycystic kidney disease (ADPKD) (4.04\%), Obstructive nephropathy (7.5\%), Miscellaneous/unknown causes (21.2\%). (Figure 1)

Out of 396 patients, 213(53.7\%) patients died by the end of first year. A significant number of those deaths occurred in the first 6 months of starting dialysis therapy. Mean time for formation of AV fistula in our study was 40days. All patients were initiated on dialysis through right internal jugular vein access.

Table 1: Comparing the variables between dead and surviving patients

\begin{tabular}{|c|c|c|c|c|}
\hline Population characteristic & Died group(n-213) & percentage & Survived group(n-183) & Percentage \\
\hline Males & 125 & $58.6 \%$ & $13975.9 \%$ & 0.015 \\
\hline Females & 88 & $41.3 \%$ & 44 & $24 \%$ \\
\hline $20-40 y r s$ & 59 & $27.6 \%$ & 64 & $34.9 \% 0.54$ \\
\hline $40-60 y r s$ & 127 & $59.6 \%$ & 24 & $51.9 \%$ \\
\hline >60yrs & 27 & $12.6 \%$ & 49 & $13.1 \%$ \\
\hline With DM & 155 & $72.7 \%$ & 24 & $26.7 \% 0.000$ \\
\hline Without DM & 58 & $27.2 \%$ & 96 & $13.1 \%$ \\
\hline With HTN & 149 & $69.9 \%$ & 87 & $52.4 \% 0.013$ \\
\hline Without HTN & 64 & $30 \%$ & 166 & $47.5 \%$ \\
\hline Hb $<10$ & 213 & $100 \%$ & 17 & $90.7 \% 0.003$ \\
\hline Hb $>10$ & 0 & $0 \%$ & 151 & $9.2 \%$ \\
\hline Ca $<8.3$ & 189 & $88.7 \%$ & 32 & $82.5 \% 0.3$ \\
\hline Ca $>8.3$ & 24 & $11.2 \%$ & 122 & $17.4 \%$ \\
\hline Alb $<3$ & 208 & $97.6 \%$ & 61 & $66.6 \% 0.000$ \\
\hline Alb $>3$ & 5 & $2.3 \%$ & 10 & $33.3 \%$ \\
\hline BMI $<20$ & 34 & $15.9 \%$ & 173 & $5.4 \% 0.01$ \\
\hline BMI $>20$ & 179 & $84 \%$ & 95 & $94.5 \%$ \\
\hline EF $<50 \%$ & 213 & $100 \%$ & $0 \%$ & $51.9 \% 0.000$ \\
\hline EF $>50 \%$ & 0 & $64.7 \%$ & & $48 \%$ \\
\hline Presence of LVH & 138 & & $40.9 \% 0.000$ \\
\hline
\end{tabular}


Table 2: Comparing the mean values between the two groups

\begin{tabular}{|c|c|c|c|}
\hline Population characteristic & Died group (Mean \pm SD) & Survived group (Mean \pm SD) & P \\
\hline BMI $(\mathrm{kg} / \mathrm{m} 2)$ & $22.43 \pm 2.93$ & $22.58 \pm 2.120 .68$ & \\
\hline UOP $(\mathrm{ml})$ & $382.9 \pm 142$ & $493 \pm 185$ & 0.00 \\
\hline Calcium $(\mathrm{mg} / \mathrm{dl})$ & $7.93 \pm 0.48$ & $7.58 \pm 0.66$ & 0.00 \\
\hline Phosphorous (mg/dl) & $4.56 \pm 0.68$ & $4.49 \pm 0.69$ & 0.43 \\
\hline Serum albumin (mg/dl) & $2.06 \pm 0.23$ & $2.96 \pm 0.28$ & 0.00 \\
\hline Hemoglobin (g/dl) & $6.53 \pm 1.35$ & $6.90 \pm 1.76$ & 0.102 \\
\hline Ejection fraction & $34.9 \pm 6.35$ & $49.8 \pm 10.2$ & 0.00 \\
\hline Interdialytic weight gain & $4.42 \pm 0.65$ & $2.5 \pm 1.18$ & 0.00 \\
\hline
\end{tabular}

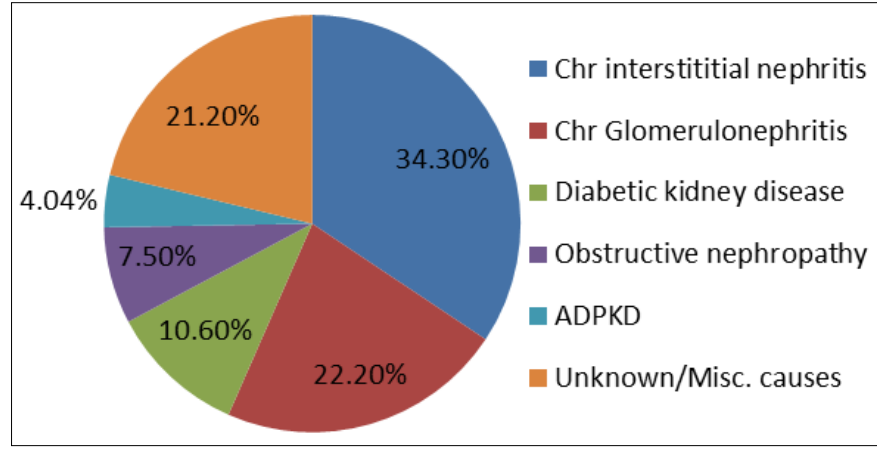

Fig 1: Etiology

Table 3: Comparing the etiology of chronic kidney disease between the two groups

\begin{tabular}{|c|c|c|}
\hline \multicolumn{2}{|c|}{ Died group (n) Survived group (n) } \\
\hline Diabetic kidney disease & 20 & 22 \\
\hline Chronic glomerulonephritis & 42 & 46 \\
\hline Chronic interstitial nephritis & 76 & 60 \\
\hline Obstructive nephropathy & 14 & 16 \\
\hline ADPKD & 8 & 8 \\
\hline Unknown & 51 & 33 \\
\hline
\end{tabular}

Among the variables compared between two groups for assessing survival using cox regression model, female sex, native kidney urine output $>250 \mathrm{ml}$, serum albumin $>2.5 \mathrm{~g} / \mathrm{dl}$ ,2Decho findings of $\mathrm{EF}>50 \%$ \& absence of $\mathrm{LVH}$, compliance to dialysis, interdialytic weight gain $<3 \mathrm{~kg}$ were found to significantly affecting the survival. In our study, no significant difference was found between those with and without diabetes in relation to survival. (Table 1\&2)

Table 4: Binary Logistic Regression Analysis to Identify Predictors of Mortality

\begin{tabular}{|c|c|c|c|c|c|c|}
\hline Factors & SE & WaldP & Odds ratio 95. \% & CI for Exp (B) & Lower & Upper \\
\hline Age & 0.058 & 0.351 & 0.554 & 1.035 & 0.924 & 1.159 \\
\hline Sex & 3.631 & 4.312 & 0.038 & 0.001 & 0.000 & 0.655 \\
\hline DM & 1.965 & 0.616 & 0.433 & 0.214 & 0.005 & 10.062 \\
\hline HTN & 2.219 & 0.003 & 0.960 & 1.118 & 0.014 & 86.580 \\
\hline Hb & 0.618 & 0.815 & 0.367 & 1.747 & 0.520 & 5.863 \\
\hline S. albumin & 3.921 & 8.649 & 0.003 & 10.17 & 4.6 & 2.21 \\
\hline LVH & 2.361 & 4.218 & 0.008 & 0.008 & 0.000 & 0.801 \\
\hline Compliance & 1.936 & 4.294 & 0.038 & 0.018 & 0.000 & 0.805 \\
\hline IDWG & 0.966 & 7.114 & 0.008 & 0.015 & 0.011 & 0.505 \\
\hline CA & 3.593 & 4.294 & 0.241 & 2.302 & 0.000 & 16.964 \\
\hline Egfr & 1.233 & 0.457 & 0.499 & 1.276 & 2.05 & 25.786 \\
\hline EF & 0.038 & 41.52 & 0.000 & 1.185 & 1.37 \\
\hline
\end{tabular}

\section{Discussion}

Analysis of our data at the end of study revealed that 213 out of 396 patients died with an estimated mortality rate of $53.7 \%$ which is considerably higher than reported by Mittal et al. ${ }^{\text {[11] }}$ (12.5\%) and Chandrasekhar et al. [12] (19.8\%). Out of 213 deaths, 140 (66\%) occurred in first 120 days after initiation of dialysis and 73 (34\%) occurred between 121 and 365 days after initiation of dialysis. In DOPPS ${ }^{[13]}$ phase 1 study done from 2007 to 2010, also reported 1 year mortality rate of $17.5 \%$ with elevated risk in first 120 days of initiation of hemodialysis. This data also compares favorably with the USRDS data ${ }^{[14]}$ which shows higher mortality rates in first few months of dialysis, especially in 2 to 4 months of starting the treatment.
In our study, mean age in the died and survived group was $54 \pm 5$ years and $45 \pm 7$ years respectively. This was similar to that reported by Chandrasekhar et al. ${ }^{[12]}$, which showed mean age of patients expired in the cohort were middle aged (50.89 \pm 17). Though males outnumbered females in this study, females had a greater risk for death with an adjusted odds ratio (OR) of 0.001 with $95 \%$ CI of $0.000-0.0065$. Female sex was found to predict mortality independently on an age-adjusted multivariate logistic regression analysis. This does not agree with the findings of Depner et al. ${ }^{\text {[15] }}$ and USRDS data ${ }^{[14]}$ who demonstrated a survival advantage in females with increased dialysis dose as compared to males. 
In our study, presence of diabetes did not have statistically significant impact on outcome. Presence of hypertension also not associated with increased risk of mortality in this study. This is comparable to results obtained by Chandrasekhar et al. ${ }^{[12]}$, in which risk of death in the died group was $94 \%$ when compared to $92 \%$, which was not statistically significant. This is in contrast to Bradbury et al. [16], who demonstrated $75 \%$ versus $22 \%$ risk of death between hypertensives and nonhypertensives, respectively, which was statistically significant.

Malnutrition is another important determinant of adverse outcome in dialysis. In our study, serum albumin was $2.06 \mathrm{~g} / \mathrm{dl}$ in died group and $2.9 \mathrm{~g} / \mathrm{dl}$ in survived group. Low serum albumin was significantly associated with increased risk of death with significant p value of 0.00 . This is similar tostudies done by Owen et al. ${ }^{[17]}$ and Dwyer et al. ${ }^{[18]}$, who demonstrated an increased mortality in undernourished patients with hypoalbuminemia. However in our study, there was no significant risk of death among patients with low $\mathrm{BMI}$ and it is not independent predictor of mortality.

In present study, mean hemoglobin value was $6.67 \mathrm{~g} / \mathrm{dl}$, which was much lower than the recommended level by KDIGO guidelines ${ }^{[19]}$. But lower hemoglobin level did not significantly affect the outcome. In our study, mean calcium levels in died and survived group was $7.93 \pm 0.48$ and $7.58 \pm 0.66$ respectively. The mean phosphorous values in the present study in died and survived groups was $4.56 \pm 0.68$ and $4.49 \pm 0.69$ respectively. The higher mean calcium values in died group was similar to those reported by Chandrasekhar et al. ${ }^{[12]}$. This findings also similar to study by Geofrey et al. ${ }^{[20]}$, in which high serum calcium and low phosphorous level were found in patients, which correlated positively with mortality and low serum phosphorous level correlated with poor nutritional status and low protein intake. But in our study, there was no significant correlation between high calcium and phosphorous values and risk of death.

In our study, dialysis related factors like compliance to dialysis and high interdialytic weight gain(IDWG)were found to be independent predictors of mortality. IDWG is regarded as surrogate of volume overload in patients on hemodialysis. (Table 3). In present study, IDWG > 3kgs was an independent predictor of mortality. This is similar to study by Lee et al. ${ }^{[21]}$, who reported high interdialytic weight gain was associated with adverse cardiovascular outcomes.

Studies have shown that preservation of residual renal function in dialysis patients was an independent factor in patient survival. In our study, native kidney urine output in died and survived group was $382.9 \pm 142 \mathrm{ml}$ and $493 \pm 185 \mathrm{ml}$ respectively which was statistically significant. This was similar to two studies by Kjaergaard et al. ${ }^{[22]}$ and Shafi et al. [23], who documented that preservation of residual renal function in dialysis patients improved quality of life as well as survival.

Cardiovascular disease is the most important cause of mortality in ESRD patients. In present study, presence of $\mathrm{LVH}$ and $\mathrm{EF}<50 \%$ were found to be independent

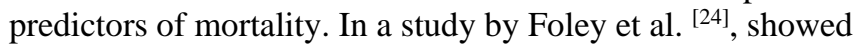
high prevalence of cardiovascular disease in dialysis patients. Cardiac disease contributes for $40 \%$ of deaths in international registries. Since all the patients in our study were initiated on dialysis with temporary right internal jugular vein access, impact of temporary access versus arteriovenous fistula on mortality could not be studied.

Our study attempts to highlight the factors associated with significant risk of mortality in hemodialysis patients. Female sex, serum albumin, native kidney urine output, low EF and presence of $\mathrm{LVH}$ in $2 \mathrm{D}$ echo, as well as dialysis related factors i.e; compliance to dialysis and interdialytic weight gain were found to be independent predictors of mortality.

\section{Conclusions}

- Increased early mortality was noted in first 120 days after initiation of dialysis.

- Females were at greater risk of death compared to males.

- Poor nutritional status evidenced by low serum albumin and Low EF and concentric LVH were significantly associated with increased risk of death.

- These data suggest that strategies to prevent cardiovascular events and improve nutrition increase the survival outcomes among hemodialysis patients.

- Poor compliance to dialysis and high interdialytic weight gain were independent predictors of mortality.

\section{Financial Support and Sponsorship: Nil}

Conflict of Interest: None declared.

\section{References}

1. Ruggenenti P, Schieppati A, Remuzzi G: Progression, remission, regressionof chronic renal diseases. Lancet 2001;357(9268):1601-8.

2. Modi GK, Jha V. The incidence of end-stage renal disease in India: apopulation-based study. Kidney Int 2006;70(12):2131-3.

3. Kher V. End-stage renal disease in developing countries. Kidney Int 2002;62(1):350-62

4. US Renal Data System: USRDS 2004 Annual Data Report: Atlas of End-Stage Renal Disease in the United States, Bethesda, National Institutes of Health, National Institute of Diabetes and Digestive and Kidney Diseases, 2004.

5. Soucie JM, McClellan WM. Early death in dialysis patients: Risk factors and impact on incidence and mortality rates. J Am SocNephrol 1996;7:2169-2175.

6. Rao M, Juneja R, Shirly RB, Jacob CK. Haemodialysis for end-stage renal disease in Southern India: A perspective from a tertiary referral care centre. Nephrol Dial Transplant 1998;13:2494-500.

7. Collins AJ, Foley RN, Herzog C, Chavers B, Gilbertson D, Herzog C, et al. US Renal Data System 2012 Annual Data Report. Am J Kidney Dis 2013;61:e1-476.

8. End-Stage Renal Disease Program Facility Sanvey Tables 1982 through 1988. Baltimore, MD, ESRD Information Analysis Branch, Division of Information Analysis, Health Care Financing Administration, 1989.

9. Cambi V. Dialysis strategies. In: Davison AM, Cameron JS, Grünfeld JP, Kerr DN, Ritz E, Winearls CG, editors. Oxford Textbook of Clinical Nephrology.3rd ed. New York: Oxford University Press Inc 2005;3:1899-908.

10. Cockcroft DW, Gault MH. Prediction of creatinine clearance from serum creatinine. Nephron 1976;16:3141. 
11. Mittal S, Kher V, Gulati S, Agarwal LK, Arora P. Chronic renal failure in India. Ren Fail 1997;19:76370.

12. Chandrashekar A, Ramakrishnan S, Rangarajan D. Survival analysis of patients on maintenance hemodialysis. Indian J Nephrol 2014;24:206-13.

13. ISN Hemodialysis Guideline Workgroup. Indian Society of Nephrology guidelines on hemodialysis units. Indian J Nephrology 2012;22:28.

14. United States Renal Data System. Excerpts from USRDS 2008 Annual Data Report. U.S. Department of Health and Human Services. The National Institutes of Health, National Institute of Diabetes and Digestive and Kidney Diseases. Am J Kidney Dis 2009;1:S1.

15. Depner T, Daugirdas J, Greene T, Allon M, Beck G, Chumlea $\mathrm{C}$, et al. Dialysis dose and the effect of gender and body size on outcome in the HEMO Study. Kidney Int 2004;65:1386-94.

16. Leavey SF, Strawderman RL, Jones CA, Port FK, Held PJ. Simple Nutritional Indicators as Independent Predictors of Mortality in Hemodialysis Patients. Am J Kidney Dis 1998;31:997-1006.

17. Owen WF, Lew NL, Liu Y, Lowrie EG, Lazarus JM. The urea reduction ratio and serum albumin concentration as predictors of mortality in patients undergoing hemodialysis. $\mathrm{N}$ Engl $\mathrm{J}$ Med 1993;329:1001-6.

18. Dwyer JT, Larive B, Leung J, Rocco MV, Greene T, Burrowes $\mathrm{J}$, et al. Are nutritional status indicators associated with mortality in the Hemodialysis (HEMO) Study. Kidney Int 2005;68:1766-76.

19. Kidney disease improving global outcomes (KDIGO) Anemia work group: KDIGO clinical practice guidelines for anemia in chronic kidney disease: Kidney international; suppl 2012;2:279-335.

20. Block G. Calcium, Calcimimetics and Clinical Outcomes. Clin J Am Soc Nephrol 2006;1:170-1.

21. Lee MJ, Doh FM, Kim CH, Koo HM, Oh HJ, Park JT, et al. Interdialytic Weight Gain and Cardiovascular Outcome in Incident Hemodialysis Patients. Am J Nephrol 2014;39:427-35.

22. Kjaergaard KD, Jensen JD, Peters CD, Jespersen B. Preserving residual renal function in dialysis patients: An update on evidence to assist clinical decision making. NDT Plus 2011;4:225-30.

Shafi T, Jaar BG, Plantinga LC, Fink NE, Sadler JH, Parekh RS, et al. Association of residual urine output with mortality, quality of life, and inflammation in incident hemodialysis patients: The Choices for Healthy Outcomes in Caring for End-Stage Renal Disease (CHOICE) Study. Am J Kidney Dis 2010;56:348-58

23. Foley RN, Parfrey PS, Sarnak MJ. Clinical epidemiology of cardiovascular disease in chronic renal disease. Am J Kidney Dis. 1998;32(3):S112-S119.

24. Hull AR, Parker TF ifi: Proceedings from the Morbidity. Mortality and Prescription of Dialysis Symposium. Dallas, TX, September 15 to 17, 1989. Am J Kidney Dis 1990:15:375-383. 